\title{
Sustainable approaches to rejuvenate the handloom and handicraft in India
}

\begin{abstract}
Handlooms and Handicrafts are one of the most important cottage industries in the country giving livelihood to most of rural India. A number of handlooms in India are engaged in weaving with natural fibers such as cotton, silk, and wool. Most of the villages in India are directly or indirectly dependent for their bread and butter on the handloom and handicraft sector. This sector carries proudly the traditional beauty associated with India's such precious heritage. A research study on one of the silk handloom sectors situated in a small village named Bhagaiya in Jharkhand was carried out with an objective to gather considered data and references reflecting the aspects and aspirations of this lively craft and its position in the region. The ambition of the research is to add perspective to the development of this craft and the craftsmen associated with it. The study was carried out with the intention to understand the existing supply chain, to gain insight through a diagnostic study of the environment, specific realities prevailing, resources available and mapping the aspects of the handloom industry practiced in the region. The study and its outcomes aims to bring forth the strength, weaknesses, opportunities, and threats. This SWOT can be used by interested agencies/Government Sector, researchers who can approach this region with an objective to provide or facilitate necessary aids that can bring about positive changes in the lives of the weaver. This paper also tries to provide insights into the handloom textile industry and attempts to explain the challenges and opportunities that lie within. This paper also takes into account the usage of cost-effective and eco-friendly technology using natural dyes from identified resources of India and which has also been evaluated, adopted and adapted by the various handloom weavers segments in India. This paper looks at handcraft as one of the potential segment for accomplishing sustainable development by examining the colorful region of Kutch and to bring forth successful elements being practiced here for a better conservation of resources and its moving towards sustainability.
\end{abstract}

Keywords: sustainable, natural dyes, natural fibers, handloom fabrics, handicrafts
Volume 6 Issue 6 - 2020

\author{
Sanjay Shrivastava \\ National Institute of Fashion Technology, Ministry of Textiles, \\ Govt. of India, India
}

Correspondence: Sanjay Shrivastava, National Institute of Fashion Technology, Ministry of Textiles, Govt. of India, Mithapur Farms, Patna - 80000 I, India, Email sanjay.shrivastava@nift.ac.in

Received: September 02, 2020 | Published: November 10, 2020

\section{Introduction}

In India, the handloom and the handicraft sector is one of the largest decentralized rural-based economic activities after agriculture. Indian handlooms have captivated the world and remains closely linked to its culture and ethos. Indian handloom Industry has an overwhelming presence in the economic matrix and is one of the main contributing sectors towards export earnings. The export of handloom products during the financial year 2017-2018 was valued at US\$353.90 million as compared to Rs.2392.21 crore (US\$ 333.59 million) in the financial yeas of 2016-17. ${ }^{1}$

The traditional handloom weaving is a part of the country's cultural ethos and it forms a precious part of its own generational legacy. It provides large employment and nearly $15 \%$ of the total clothes produced in the country are from this sector. The strength and key areas of handloom products is that it believes in introducing of innovative designs and at the same time keeping its heritage elements intact such that replication of the same on power loom will be difficult. The lack of market and the demand for handloom products along with too many government interventions has over simplified the diversity of this sector. This has made the weavers more dependent on such schemes and has over the years negatively impacted on the potentiality of their entrepreneurial spirit. The government has treated this sector as a rural enterprise and have been offering different schemes for its survival. The initiatives like Make in India aims to ignite the dying aspiration of many a weaver and help them to get their products recognized for a better world standing in terms of its visibility and viability. There has been attempts on similar lines by host of other schemes which may also add potentiality to the position of the weaver leading to creation of more opportunities in the economy. These schemes which are popularly known as 'Skill India', 'Digital India', 'Brand India' 'Swadeshi Products' 'Aatam nirbhar Bharat (self -independent)' 'Vocal for Local'. All these initiatives have given the weavers a new momentum and the results accumulating out of the combined efforts have already started showing positive results and as a result leading to a much better position of handloom and handicraft rural industry. "Vocal for local" should become the mantra for every Indian as the traditional art forms being practiced over the looms still continues to rattle well enough so as to increase its presence and still continues to be in harmony with the industrialization at large. ${ }^{1,2}$

What has been seen is that the ever-increasing importance for a holistic growth in the Indian handloom sector has been directly affected by many factors such as individual growth of organized and unorganized textile industries, social and political influencing parameters, and by the governmental policies meant for the textile sector. A systematic review of the present scenario of the Indian handloom sector has been depicted in this paper. The overall facts and findings can help the stakeholder to formulate strategies to the already existing practices. India as a country has created a niche of its own when it comes to making of high-quality fabrics. Those who have been able to acquire the skills of working as handloom weavers or hand spinners have been a key segment in the Indian culture in the sense that their services have always been in high demand. ${ }^{3,4}$ The 
Handloom area assumes an essential part of the nation's economy. The economic liberalization, uniqueness, flexibility of production, openness to innovation, adaptability to the supplier's desires, cluster approach, strategies to aggressive marketing, and implementation of various social welfare measurements have shown a positive sign in the growth of Indian handloom sectors. Especially when the quality of Handloom lies in its own creative outlines and the same becomes difficult for the power loom sector to replicate (Table 1).

Table I Cloth production by Indian Handloom Sectors (in million sq. meters) (Annual report 20I7-I8, Min. of Textiles, GOI)।

\begin{tabular}{lllll}
\hline Year & $\begin{array}{l}\text { Total cloth } \\
\text { production* }\end{array}$ & $\begin{array}{l}\text { Cloth production by } \\
\text { handloom sector }\end{array}$ & $\begin{array}{l}\text { Share of handloom in total } \\
\text { cloth production }\end{array}$ & $\begin{array}{l}\text { Ratio Handloom to Powerloom } \\
\text { (in terms of cloth) }\end{array}$ \\
\hline $2010-11$ & 61761 & 6907 & 11.18 & $01: 05.5$ \\
$2011-12$ & 59605 & 6901 & 11.57 & $01: 05.4$ \\
$2012-13$ & 61949 & 6952 & 11.22 & $01: 05.5$ \\
$2013-14$ & 62624 & 7104 & 11.34 & $01: 05.2$ \\
$2014-15$ & 64332 & 7203 & 11.19 & 0.376388889 \\
$2015-16$ & 64584 & 7638 & 11.82 & $01: 04.4$ \\
$2016-17$ & 63480 & 8007 & 12.61 & $01: 04.9$ \\
$2017-18$ & $43520(\mathrm{p})$ & $5134(\mathrm{p})$ & 11.8 & \\
\hline
\end{tabular}

*The total cloth production includes handloom, power loom and mill sector excluding hosiery, khadi, wool and silk

Most of the states in India are only $20 \%$ urban having presence of relevant industries. Along with agriculture, education, health, handloom and handicraft sector are important segments that have been crying for attention in many states of India. The handloom and handicraft sectors in India have had strong linkages with the agriculture regions in the states. These are presumed to be the evidences leading to acute capital scarcity in the sector. ${ }^{5}$

Bhagaiya is a craft cluster in Jharkhand, where handloom weaving is being practiced for more than over 100 years. The weavers including women and children of the household actively take part in the practice of this craft. The changing dynamics of the fashion industry and its impact on the lifestyle, income, design process, design innovations, final products, marketing, etc is quite evident today and the survival lies into the basic fact of understanding the USP of these Handloom Sectors and identifying way forward towards new market zones which should not be limited to the areas in which it is practiced. The strength of this sector lies in its own uniqueness, added to it being less capital intensive, usage of minimal electricity, tagged as having eco-friendly quality, flexibility of small production, adaptability to market requirements, openness to innovations and carrying forward of the traditions. This sector faces challenges and immense competition from the price aggressive power-loom industry and also in terms of skills, aesthetics, contemporary methods, infrastructure and supply chain. Unavailability of raw materials at the right time and at regular rates, inefficient advertising and marketing tools and sales procedures add more worries for the survival of the Handlooms. The government has identified this business as a rural venture and has provided various initiatives and policies for its revival. The government's 'Atmanirbharta' program, the 'Vocal for Local' campaign, together with 'Make in India', presents a huge opportunity to the handloom sectors which can strengthen and position it in the global textiles space. In India, the handloom sector is one of the largest unorganized economic activities after agriculture and constitutes an integral part of the rural and semi-rural areas with over 4.3 million people, directly and indirectly, involved in the production.

It has been seen that the Potential associations among crafts and sustainable development methods have together helped handcrafts to move towards a more progressively economic social order. Craft of any nature as such offers various influences which focuses on aspects of connections between monetary and instructive models leading to mapping of sustainable development. This contribution can be an option and a mechanism to move towards an increasingly imaginative diverse meaning of "sustainability" which will help it to take it further into "tirelessness" of specialty and its job in "present-day" social scenarios context. This will be an way out for a constructive evaluation for assessment of such domains. The evaluated aspects examined the work as a mechanism to improve the comprehension of the manners by which contemporary craft is rehearsed and in connection towards development towards sustainability. Attempt has been made to place a prologue to craft for sustainable development and to also review crafts practiced in region of Kutch for drawing parallels into the findings.

\section{The performance-based factors for the Indian handloom sector}

There are few Sustainable approaches which can be easily adopted to rejuvenate the Handloom Weavers in India and that they can help identify areas where it can be implemented. The areas may relate to marketing and publicity support; welfare measures; infrastructure supports; composite growth based schemes leading to modernization and machinery up-gradation in technology; Development in import and export scheme; Wages, employment and livelihood issues; tackling unfair competition from mills and power looms; enhancement of Value; eliminating Intermediaries; better Cooperative system; patenting designs/varieties; design improvements; raw material supply and prices; ensuring adequate and timely credit supply; illiteracy and poverty among weavers..$^{1,2}$

While examining the potentiality of sustainability in the region it is necessary to ensure that the weaker sections who are dependent for their livelihood on Handloom and Handicraft do not experience distress due to adverse competition from Power loom. It is also necessary to ensure that these rich craft and traditions return in terms of higher wages for the artisans. This would be possible only if the demand for these products starts commanding higher prices both in 
the domestic as well as international market. This would need rigorous and sustained promotional efforts. It has been observed that in the last two decades several state govt. who have realized the employment and value addition potential of the textile and handloom sector have come out with their own Textile policies tailored to attract investment in specific sub-segments and specific areas within the State.

\section{A case study on Bhagaiya, Jharkhand: unraveling the weaver's scenario}

The main aim of this survey was to study considered data and the lively components of the craft and its status at Bhagaiya, Jharkhand. This was done to bring out the aspects and important elements needed for the progression of this craft and the craftsmen. This research has tried to understand the distribution chain, map the practices through a diagnostic research and understand it in the way the handloom sector is performing across the country. In the process the gap between the past and the current practices in this craft was ascertained and the difference between the supply and demand was addressed. Further attempts to find out the changes and advancement in the design of the products over the years also resulted in an interesting roadmap.

Apart from the general practices limited to this trade, here it was found that the dry cocoons (called 'Goti' in the local language) are brought from the market of Jagdalpur, Chattisgarh at the rate of Rs.6 to 7 per piece. Apart from this the other raw materials used are tussar silk cocoon, soda, sugar, khapra (local language) and water. The preparation work is done manually by the female members of the family. No part of the cocoon is wasted as the left over's are dried and sold in the market. This normally is used for doing design innovation by the weavers. The looms and other accessories used for weaving are Natua (wooden-framed conical spool used to wrap the yarn around it), Rehti (wooden small-sized charkha), Bobbin or Pirn, Charkhi (Wooden or iron tool used to transfer yarn from hank to bobbin) and winding machine.

After the yarn is extracted from cocoons it is subjected to drying in sunlight. The dried yarns are then wrapped on a tool locally called Natua which is used for warp yarn and weft remains in the shuttle for weaving (Figure 1).
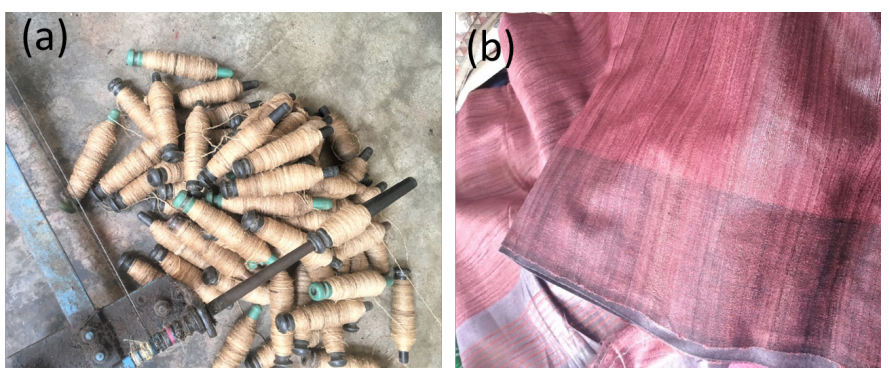

Figure I (a) Pirns with Ghicha silk winding, (b) Tussar silk saree.

In the weaving process, it has been observed that the male members of the village are generally involved from setting up the loom till the fabric is woven. Extensive use of Korean silk yarn was being used for warp due to its characteristics of being translucent in nature and having higher strength. The Korean silk yarn gave the fabric an even and more colorful tone while making plain weave but of late it is being used for twill also and its derivative weave types. There are mainly three types of products used such as tussar ghicha (also called TG is in demand) dress material, sarees, and stoles. The fabric generally has tussar as warp yarn and ghicha as weft yarn. This material is mainly used for making of shirts and kurta. The materials are mostly exported to Delhi, Bangalore and Kolkata, where the demand for TG is higher. Earlier only plain sarees were weaved in the loom but during the past few years, weavers and designers have introduced new designs. Sarees are now made of various designs, and some are made using ghicha silk, some are made with pallu having ghicha silk and some have borders of zari. Weavers normally work on these design which is ordered by Mahajans (Middlemen). Embroidery work is slowly becoming an integral part of all sarees and today sarees and shawls can be seen with beautiful embroideries. The demand of these products are less in the local market due to the cost factor which seems higher for the region. The weavers make these products only on confirmed orders which may be as new designer product. In spite of the hardships and problems being faced in selling the traditional motifs, most of them still want to follow the traditional design that was practiced earlier.

The handloom sector in India has been gaining its position as the demand from the market is increasing. After Jharcraft has been set up, the weavers including their families are being provided with various subsidies governed by various government policies state or central. They are also provided with skill education in various fields of textiles. Most of the weavers have set up looms in their houses supported or funded by Jharcraft.

\section{Opportunities for handloom weavers using natural resources}

Before the beginning of the $20^{\text {th }}$ century, all colors used for textile coloration came from nature, there were no other alternatives by which it could be produced. Natural dyes were the only source of color available until the turn of the century; therefore, they were widely used. After the discovery of synthetic dyes by William Henry Perkin in 1856, there was a complete change in the way the same was practiced. Since synthetic dyes have moderate to excellent color fastness properties, the demand and use of natural dyes having poor to moderate wash and light fastness properties as against synthetic dyes stated losing its demand. Unfortunately, the natural dyes are rarely used in modern dyeing nowadays, except by some companies and craft dyers supporting the cause of organic trade. Today synthetic chemicals that are used in different dyes for the textile industry have become some of the principal sources of environmental pollution. Synthetic dye substances cause allergies in human beings and also has several carcinogenic properties. On the other hand since natural dyes are obtained from renewable resources and they do not have any health hazards, they are biodegradable and are non-toxic; they are once again getting importance owing to the growing awareness of environmental problems coupled with the toxicity associated with the use of synthetic dyes. In addition to that, some of the natural dyes have good antioxidant and medicinal properties. Because of this natural dyes are commonly used in the cosmetic, food, and textile industries due to their no harmful side effects, UV protection, and anti-aging properties.

The importance of environmentally friendly antimicrobial agents derived from natural products and its application on textiles have has had a great past and is looking for a great future. Natural product- based bioactive agents such as natural dyes, chitosan, neem extract, and other herbal products were reviewed for their antimicrobial activity on the textile substrate. The mechanism of antimicrobial action had been presented along with that a brief review of the active ingredients found in extracts of natural products was also done. Dyeing property of soybean protein fabric using natural coloring matter extracted from marigold and tannin mordant such as tamarind seed coats, amla and 
harda (Myrobalan fruits). The antibacterial property of cotton dyed samples was also investigated. The colorfastness properties including light, washing and rubbing of dyed and mordanted fabrics were assessed. The results of the fastness properties of the cotton dyed fabrics were fair to good.

Handloom fabrics become much better after the natural plant resources such as coloration, antibacterial, ultra-violet protection and flame retardant properties using coconut shell extract, Sterculiafoetida fruit shell extract, Delonixregia stem shell extract, temple flower waste extract, etc was used. The effects of different functional properties of natural resources using the plant, animal and clay on the performance properties of the handloom textile materials can be used for valueadded products. ${ }^{6-11}$ The hand-painted fabric has the potential for giving an elegant look to various handloom fabrics used for apparel and home furnishing purpose. Efforts were also made to create khadi clothes more appealing with advanced design interventions through printing using colorants extracted from organic sources. ${ }^{12,13}$

\section{Handicraft: A contributing factor towards sustainability}

'Craft' is typically interpreted as an article that has a high level of hand-made and man-made features, however, which isn't made or structured utilizing conventional materials. Craft most of the times is created for smaller groups and hence its impact on coming generations is not normally felt. Further such makers have reduced in number due to the trade not being economically viable. Today any craft must possess some of the key elements that has the potential to affect the economic viability of the Country. The craft sectors have been an ignored area even though the craft sector is projected as patterned and dynamic. There are many avenues for raising awareness of various craft disciplines and how to use it for sustainable fashion. If there can be a steady spot light on it, the resistances towards it and the movement towards mass-created and institutionalized items would not be that critical.

The significant modernization and its alarming usage of the resources have over the decades depleted the earth and its environment leading to troublesome changes in the atmosphere. The extensive usage of resources are crying for attention and various platforms are making pathways for defining and redefining what is meant by sustainable development.

The concept of sustainable improvement depends on the concept of innovation (monetary development by herbal necessities), the concept of requirements, and the idea of who and what is to come back. The essence of any such feasible improvement receives its essence from ecological help with an aim to concentrate on retaining the nature and its balance. Nowadays, the possibility of maintainability and reasonable development has appeared many a corner with changing interpretations and responses. This implies that continuous efforts to enhance the range of the product's existence cycle, from raw material, manufacturing, design, production, storage, shipping, advertising, and to the very last sale is being recognized and now being extensively practiced.

\section{Case study for crafts of Kutch}

The impeccable and endlessly imaginative customs of Kutch remain alive due to the beautiful convergence of societies and cultures. Kutch has a huge advantage due to the amount of ocean exchange that it can interplay with (Figure 2). While weaving has turned into a specialty synonymous with Kutch, other artworks and specialties have given this land unique shading and character. Art and craft are inseparable from the various communities, associated in terms of trade, agriculture in Kutch and is popularly known as Khamir.

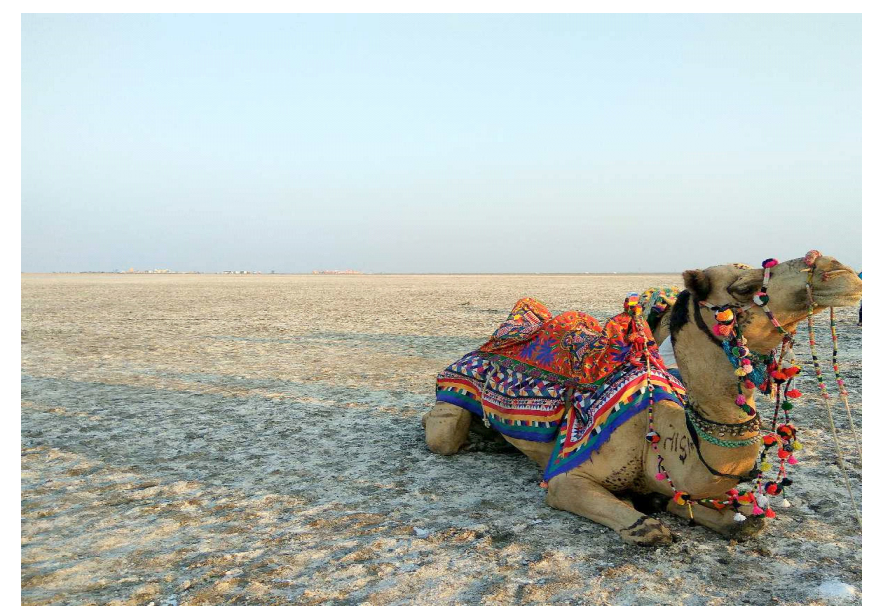

Figure $\mathbf{2}$ The mesmerizing picture of Kutch.

Khamir signifies 'natural pleasure' in Kutchi, the community language. Khamir attempts to reinforce and improve the rich and high conventions related to this place which has its own Heritage, Art, Music and related Information and Resources. Today, it fills in beautifully as a stage for the development of conventional crafted works and unified social practices, the strategies engaged with their introduction, and the conservation of subculture, community and community conditions. The endeavor to make it more popular and an engaging space, special attention is being given to provide scope to interested partners who can trade ideas and work hand in hand. The work is more focused on the purchaser point of view and at the same time to the social worth put on the artworks. Their vision is of a dynamic Indian environment in which artworks and craftsmen both can command high esteem by individuals around the world (Figure 3).

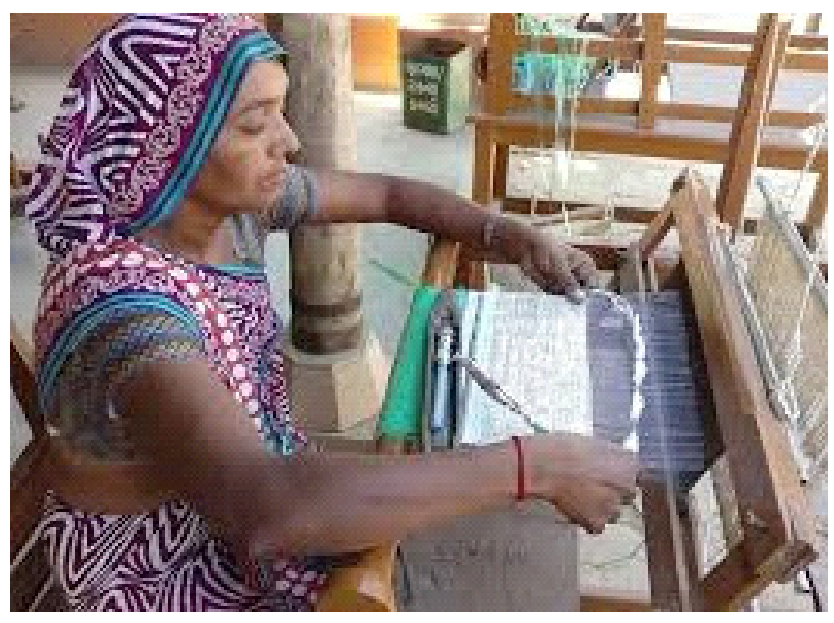

Figure 3 The organization - Khamir.

Kutch is a hub for a variety of crafts that are colorful, vibrant, and contribute towards sustainability (Figure 4). These are listed as Ajrakh block printing, Bandhani, Batik print, Bela print, Camel wool weaving, Embroidery, Kutch Weaving, Kala cotton, Kharad Weaving, Mashroo Weaving, Cattle Bells, Namda, Pottery, Recycled plastic weaving, Rogan Painting.

When we hear the world is humming with "sustainability" and "environment friendly", this place has already made its mark in the 
areas of the same with its huge patterns, endless designs in the craft that have existed and coexisted amicability with nature. Products made here have the uniqueness of being subtle but still remain so striking that the visitors cannot resist the opportunity to value the style in their own very unique creation. Amongst the basket of such unique craft, one such craft is the Ajrak. Generally, Ajrak is the name of a block printed fabric with deep crimson red and indigo blue background, bearing symmetrical patterns with interspersed unprinted sparkling white motifs. An old craft, the historical backdrop of the Ajrak can be followed back to the civic establishments of the Indus Valley that existed around $2400 \mathrm{BC}-1400 \mathrm{BC}$. Ajrakh fabric conveys numerous meanings. The prominent story practiced by printers is that Ajrakh signifies "keep it today". It is likewise connected to Azrakh, the Arabic word for indigo, a blue plant that flourishes in the bone-dry nature of Kutch. Ajrakhis depicted through complex geometry patterns to make starry constellations in indigo, madder, white and dark crosswise over lengths of material. The shapes and themes of Ajrakh look like the architectural forms of Islamic design's many-sided jali windows and trefoil curves.

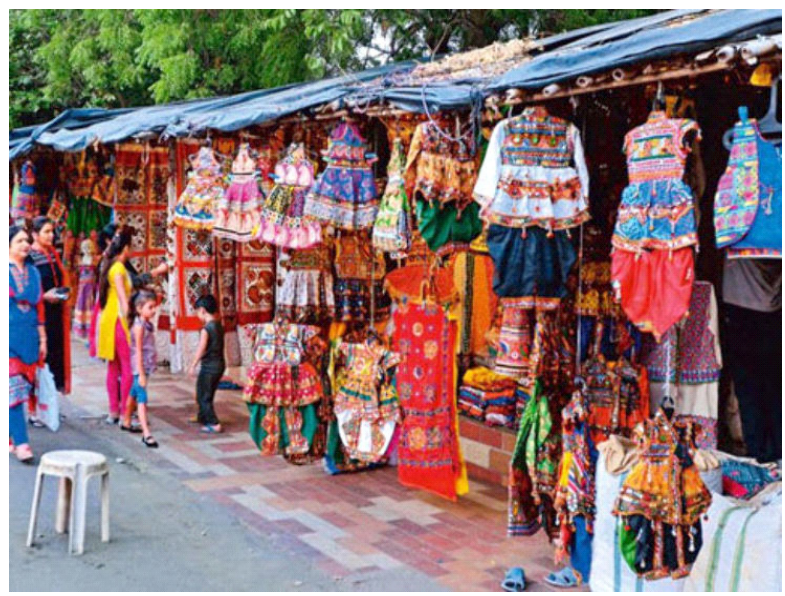

Figure 4 The market of Kutch.

Ajrakh is a noble seal for the nearby communities of Kutch Roaming pastoralists and farming groups like the Rabaris, Maldharis, and Ahirs wear Ajrakh printed fabric as turbans, lungis, or stoles. The material is made in a sixteen stage procedure of washing, coloring, printing, and drying, which requires an abnormal state of aptitude and focus to keep hues quick and even. Pomegranate seeds, gum, Harde powder, wood, flour of Kachika, the blossom of Dhavadi, alizarine, and privately developed Indigo are only a portion of the characteristic assets of this art (Figure 5).

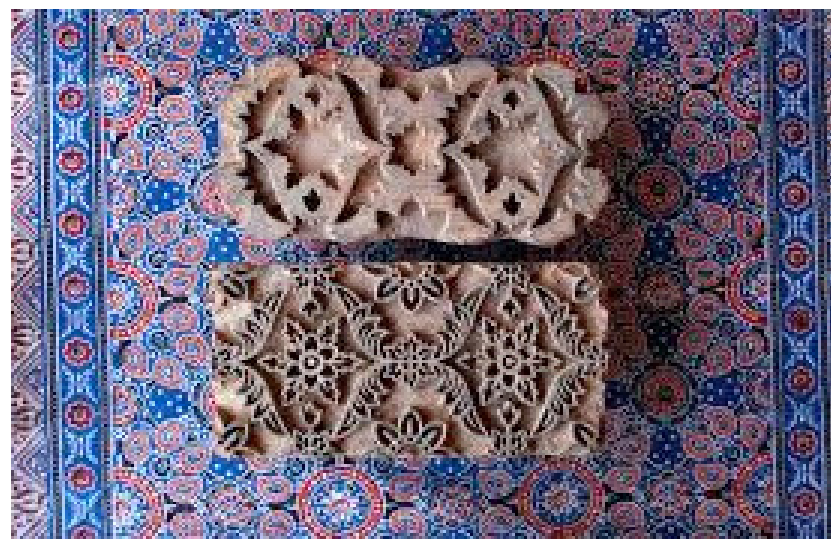

Figure 5 Ajrak block printing.
Chemical dyes are a noteworthy source of contamination in block printing towns. Different lethal colors and synthetic concoctions are discarded in-town fields with no type of treatment. These synthetic colors are modest and moderate, effectively made in mass. Today, a couple of printers utilize vegetable colors. Characteristic assets once used to make regular hues are never used locally on account of the biological impacts of the 1946 and 2001 earthquakes and the loss of life spread from ongoing industrialization.

Earlier the block printers had a stable customer base. Presently with the increasingly reasonable manufactured fabric and a shifting marketplace, the network linkages established have lost their faith and trust. As a result numerous conventional dresses and prints have seen an end. The conventional lungi is also losing its aura. Different items like Pada are likewise being worn in manufactured textures all the more regularly. Kanbi Patel ladies have embraced synthetic saris as their outfit. Generally, printers make dress material for national and global purchasers in a profoundly competitive market.

Water management issues represent a danger to coloring and printing rehearses in Kutch. Through a progression of studies, Khamir has recognized a focal need to revive water tables with better water management. This incorporates encouraging water treatment in towns and making frameworks for reusing water utilized in coloring. Understanding the prompt requirement for water security, Khamir did the pilot study and implementation of the water treatment through a small Effluent Treatment Plant. Supported by these outcomes, Khamir is currently working with the craftsmen to build up an enormous scale treatment plant to be overseen at the town level. Advancing eco-accommodating colors alongside better treatment practices will expand the supportability of the neighborhood nature and their specialty. Apart from water, Khamir has made different adaptation to consistently renew this part. This incorporates presenting new blocks, products, and raw materials to the printing families and encouraging stages to exhibit items all over India and universally. The Ajrak is for the most part is about 2.4-3meters long. The actual Ajrak is imprinted on the facets through a method referred to as resist printing. The printing is completed by using hand with hand-reduce woodblocks. A few wonderful blocks are utilized to present the trademark endured designing. Making the blocks is a considerable test considering the instance wishes to synchronize splendidly with the entire of the Ajrak just as spread specific zones towards dye. The Ajrak print is employed inside a grid, the repetitive pattern growing an internet-like design or the important jaal. Apart from this jaal, border designs also are employed inside the material. These borders are aligned both vertically and horizontally and body the crucial area, distinguishing one ajrak from every other. The lateral ends have revealed the usage of a much broader, double margin to differentiate the layouts of borders. Ajrak printing is a long procedure including numerous phases of printing and washing the texture again and again with different characteristic colors and mordants, for example, harda, lime, alizarin, indigo, and even camel dung. The system of resist printing permits restrictive assimilation of color in the ideal parts on the zones proposed to be left uncolored. The raw material is pulled very well thru the river normally, scoured, beaten, steamed, mordanted, revealed with resist mud glues from the banks of the river, secured with powdered camel dung and ground rice husks; colored in deep madder and indigo.

Unlike other approaches of printing on cloth, in which the color is carried out without delay to the fabric, in Ajrak block printing, the fabric is first revealed with a withstand paste after which it is dyed. The procedure is repeated again and again with special types of dyes, to subsequently acquire the final sample within the deep pink and blue 
colors. This sluggish technique is also very time-ingesting because the longer an artisan waits before starting the next step, the prints come out more shiner and last long. The entire process can take up to two weeks to ensure the beautiful fascinating patterns of the Ajrak. Water is essential to the creation of Ajrak cloth. Craftsmen take the cloth through a procedure that can include more than thirty separate strides as first the fabric is made ready or be mordanted and then colored. Through each stage, the character of the water will impact everything - from the shades of the hues themselves to the success or failure of the whole procedure.

Bandhani otherwise called Bandhej; is a kind of tie and dye craft that is enhanced by culling the fabric into numerous ties that form a design. The word Bandhani comes from a Sanskrit word 'Banda' which signifies 'to tie'. The technique of Bandhani includes dyeing the fabric which is firmly tied with a string at several spots to deliver various patterns.

In Kutch, tie and dye textile is known as "Bandhani". Bandhani goes back to the twelfth century and came to Kutch when individuals from the Khatri people group relocated from Sindh. Bandhani tie and dye found a place with the East India Company in the eighteenth century. Much like the local block printers, bandhani craftsman utilized available natural resources like madder and pomegranate to color their fabric with a huge array of tones. The system of firmly winding a string around a segment of cloth and then dyeing it. The design after unwinding of the string is so mesmerizing as the designs take up a circular depiction. After the 1946 earthquake of Kutch, synthetic dyes made their way to the way bandhani as a craft was practiced. Synthetic dyes are cheap and affordable and the easy availability of the same slowly eradicated and limited the utilization of vegetable dyes.

Today, the Khatri people are the main producer of Bandhani in Gujarat, keeping up with the dominance of the art that has been with them for ages. Khatris in Kutch are generally Hindus or Muslims. The demand for intricate designs featuring Bandhani is high, and the most current patterns can feature upto having one lakh ties (dots). Bandhani is utilized for day to day clothing and during auspicious occasions like birth, weddings, and worship. Khatris are making new forms of Bandhani to fit the desire of modern and increasingly global customers. They try differently with the size, shape, and situation of each dot on the fabric to offer an entirely different range of items.

Seeing the need to control the utilization of synthetic dyes in Kutch with the goal to restrict further biological harm done to the earth, water, and individuals, Khamir started activities to popularize and show the estimation of natural dyes, making natural dyestuffs increasingly available to the present-day craftsman. Khamir has directed workshops and training with Bandhani craftsmen to open them to progressively sustainable practices. The fabric is tied finely with strings and dyed in stages in various hues. The tied material when opened outcomes in different examples and themes. The plan for Bandhani is transferred onto the material utilizing shading. A plastic sheet with pinholes pattern of the design is utilized as a stencil to move the motif onto the fabric. Then again the design is blockprinted on the material.

The printed pattern zones on the fabric are then pulled up and tied firmly with string into a bunch called a bindhi. The material is pulled by squeezing with the assistance of the fingernails or with a little nail shaped metal ring, and then firmly tying it around with a string. This forms the dye resist region of the fabric. The women artisans for the most part complete the tying work. To make finer dots the pulled zone of fabric should be much smaller. For greater areas, the fabric is tied in knots of differing sizes. The tying procedure is done securing the area meant for creating the design. The strings utilized are generally cotton or synthetic nylon. The string might be covered with a resist material in the case of cotton string. The string is persistently twisted from knot to knot without cutting. This empowers the string to be reused again for various occasions. After the fabric has been tied, it is washed to expel the fugitive color imprinted on the cloth. The material is dyed with a light shade, for example, yellow. After the first dye, the free knots on the fabric are re-tied in a fixing procedure. For a complex design, the resist tying happens more than once in different sizes according to the design. The fabric is dyed again for different patterns if any and afterward washed and dried. The fabric might be progressively tied and dyed in different hues for multi-colored designs.

Batik is an old art that uses wax and dyes to make a visual enchantment on fabric. It is accepted that the term is a derivation from the word 'Ambatik' which when interpreted represents a piece of fabric with little dots or composing with wax or drawing in broken lines. It is workmanship valued everywhere throughout the world. There are changed speculations about the place and time of the beginning of Batik. In India, the underlying foundations of Batik can be traced to the first century AD. Customarily, the Khatri group of Gujarat were the main set of craftsman for this workmanship. Over a while, Batik got consigned to the foundation in India. However, in the twentieth century, Batik was presented as a major aspect of the prospectus in the University of Shanti Niketan - Kolkata. Subsequently, the resurgence of Batik started. For quite a long time, customers were happy with the botanical and figural motifs of Batik. Batik possibly was the number one enterprise in Kutch at one time. It turned into huge fabric export to Indonesia and since then Indonesian populations have been in particular connected to the Gujarati madder, a darkish purple shade dye that also became essential to their locale.

Initially, Batik prints were made via plunging a block into hot piloo seed oil, which was then pressed onto the fabric. After coloring, the oil glue was stripped off to find a print. The adoption of wax changed the look of the fabric. In wax printing the slim entices of dye run through the motif creating a lovely veined appearance and the same is much in demand. Wax print batik thrived in Kutch for the duration of the 1960s due to the artistic endeavors and growing in global sectors addressing the Hippie culture. The rise of chemical dyes did not impact the Batik and the way it was done as it could not give the impact being seen before.

Batik craftsmen nowadays are scuffling to remain afloat in a complicated and competitive market. Their style of printing is in most cases repeated by screen and laser printers, which could make textiles in larger quantities to sell in mass. Post-60's the ubiquity of Batik started blurring and giving ways to the new dimension of fashionable product emerging out of industrialization and extensive use of chemical dyes.

Before Khamir, Shri Vivekanand Gramodyog Society labored for a long time as of now to revive Batik. Khamir mediates through running with craftsmen to adopt new blocks, patterns, and collaborators so that Batik printers modernize their art and make it saleable. Khamir has likewise discovered a way to document and archive oral narratives of Batik on this location, to be able to help the historical past of the craft as a source of data, motivation, and records for destiny Batik printers 
and consumer networks. Through information about the marketplace, Batik craft can be sustained.

The artwork of batik is a three-stage method of waxing, dyeing, and dewaxing (removal of the wax). There are likewise a few subprocedures like setting up the cloth, tracing the designs, extending the cloth on the body, waxing the sector of the material that does not need dyeing, putting in place the dye, dipping the fabric in dye, heating the cloth to evacuate wax and washing the cloth in a cleanser. The trademark effects of the batik are the excellent breaks that display up within the wax, which enable small quantities of the dye to seep in. Batik wax practices an essential characteristic within the manner of batik printing.

Appropriate use of wax consequences into a flawless batik work. 30 percent beeswax and 70 percent paraffin wax is commonly carried out. During application, wax needs not be overheated or it will burst into flames. The normal batik fabric that brings out extraordinary batik prints are cambric, poplin, voiles, and natural silk. Natural coloring agents collected from barks of timber, leaves, blooms and minerals is applied.

Bela prints are intense and realistic. They catch your attention with a lively palette of printed color on a plain white background. Various tints are accomplished utilizing natural and vegetable dyes. Bagru, Rajasthan, is most celebrated for producing this kind of mordant printed textile. However, Kutch has been a producer area of Bela-style material for whatever length of time that individuals can recollect. Quite a while in the past, East Kutch delivered numerous mordant resist fabrics commonly referred to as Patthar, which were utilized as dowry gifts. Red and dark hues are iconic of Bela printing, colors that were utilized the most for their color fastness. Bagru frequently includes huge scale and graphic prints, characterized by a solid mordant-printing method wherein the printer applies vegetable dye directly to a piece of fabric with a wooden block. Khamir is attempting to revitalize Bela-style printing to make inventively designed printed bags and bolts of fabric in deep reds and rich blacks.

Kharad Weaving is a sort of one of a kind weaving technique. This art was practiced by a couple of groups of Marwada, Meghwal and Sodha Rajput people group. Customarily, Kharad was utilized as floor covers in winter. This craft was extensively practiced all through the Rann of Kutch. The common raw materials required for Kharad Craft are fleece and vegetable colorings. Kutch has a powerful custom of animal farming. The availability of camels and other domestic animals like goats and sheep become an excellent source for fleece. Initially, Kharad rugs have been produced using goat and camel hair fleece. The Maldharis and Rabaris shear the hair from camels and goats. This is given to the hand-spinners who make fleece out of the goat and camel hair which is used for making of floor covers.

Moving towards a more sustainable environment, the plastic waste is collected by agencies in the area. The plastic pieces of various hues are woven into strong materials. Nylon is utilized for the twist, and plastic structures the weft, making thick material helpful formats, knapsacks, or pads. Weaving is a skill intrinsic for the Kutch, and the reused plastic is woven utilizing an innovation old to Kutch - the pit loom. The Recycled Plastic activity is a case of how art can adjust space and create additional source of income generation for marginal people. This is an aptitude that can be effectively put in place by neoweavers and that can add value to the waste and the earnings.

Khamir is working towards overturning local stigmas associated with waste reuse by introducing plastic woven items into the local community. By reusing plastic backpacks for younger students, and making powerful and alluring items, Khamir is attempting to create an impression about the goodness of reuse of waste.

Gujarat is famous for its fine folk embroideries. Each of the Kutch's numerous networks has a particular weaving convention that has been passed on for ages from mother to the daughter. This weaving with its rich structures has made a striking commitment to the Indian weaving customs. The weaving rehearsed regularly by ladies is commonly done on textures of cotton, as a net using cotton or silk strings. In specific examples, it is additionally created over silk and glossy silk.

Today, Kutch is home to various kinds of weavings that embellish the area's dress and textures. Probably the most visible weavings include Jat, Ahir, Sodha Rajput, Rabari and Soof. Women in each community embroider using specific stitches and motifs as a form of individual and community expression. For instance, Sodha Rajput ladies wear an embroidered choli and coat after marriage, while widows wear a plain and dull colored material.

Mashroo was a craft specialty, delivered in huge amounts until the 1900's for local elite markets. The Maheshwari weavers practiced this craft. The Mashroo material was woven for Muslim people, who thought that silk should not touch an individual's skin. The significance of Mashroo is "this is permitted". The port town of Mandvi is at the focal point of Mashroo heritage in Kutch. In the areas of Saurashtra and Kutch, ladies stitch mashroo kanjari (bare-backed pullovers), skirts, and cholis. Mashroo helped weave communities together. The Ahir Patels created cotton, which was handspun and afterward given to the weavers. Rabari and Ahir ladies did weaving and mirror work to make variants of mashroo. Today, customary mashroo weaving is on the verge of extinction. The dressing styles of the Kutch individuals have changed, serving the native community linkages. Mashroo material can be made by power looms today, which individuals prefer to the more expensive handmade mashroos. With a declining export house, mashroo weavers are utilizing cotton staples rather than silk to meet the value needs of the local market. The first mashroo of cotton and silk, with its rich surface, isn't produced any longer because there is no market for this product. Mashroo is woven with a 7 to 12 peddle loom which requires the craftsman to skillfully move their hands and legs in harmony. There are eighty strings in a mashroo per inch, which is a lot higher than in a standard woven material. It is hard for a weaver to make a piece that is both enormous in size and high in thread count, thus Mashroo is just accessible in a width of 23 inches. The unadulterated silk once used to make Mashroo was later supplemented by silk, rayon and staple cotton.

Like other crafts, the art of copper covered bells advanced from the need of the time and district. Live-stock was a noteworthy occupation in Kutch. The Lohar people group from Sindh, (presently in Pakistan) saw the potential for their specialty and carried the art to the place where there is Kutch. The majority of the copper bell craftsman want their next generation to take up the art as an occupation. Copper bell making included materials like mud, the wood of 'Prosophis Julifera' and water. Mud was effectively accessible at Zura town and water is not much needed, bell producers have announced a shortage of good quality wood as the charcoal producers use up huge parts of 'Prosopis Julifera'. The metal bell craftsman has been supported since the last 40 years through a business association with a noteworthy purchaser from the US who purchases these chimes as Christmas stock.

In Kutch, the Pinjara and Mansuri people group make felted Namda from indigenous sheep fleece. After the fleece is gathered, cleaned, colored, and packed into sheets, craftsmen make brilliant and 
multifaceted structures that are frequently weaved. Namda is used to make seat covers for horses and camels and Supplication mats. Khamir is working towards bringing these crafts to a forefront and keeping the sustainability factor sin to huge consideration..$^{14,15}$

\section{Conclusion}

The handloom textile is highly fragmented and labour-intensive. Case study of the weavers who have been practicing their traditions generation after generation still reveal the ordeal that these pathways face when competing with the ever changing dynamics of the needs of the customers and the economy at large. The way they still hold on to pit looms and traditional designs is mesmerizing and every weaver has their own unique story which cannot be defined easily. What comes out is that the changing consumer appetite for newness and variety, the model of how we make and purchase challenges all the opportunities which are made available to the Indian handloom sector. The government policies and other approaches can rejuvenate the Handloom Weavers in India but one cannot sit on one BODMAS rule. Every region has its own ambition and purpose and that is why the regions become unique and hence their requirement also becomes unique.

Potential associations among handicrafts and sustainable development from the case study of Kutch. Craft, as we can put, has done a lot towards bridging the gap between sustainable development and design. Various examples of crafts from Kutch which are made from recycled materials or are in some way sustainable and a path towards sustainability. It also emphasized how craft is a very important way forward towards sustainable development and how the crossing points among the crafts of Kutch play an important role in sustainable development for a better future in India. India's Government has put up great efforts to make handloom clothes and handicraft attractive with the latest and innovative design. The rural economy in India has to be strengthened by strengthening the Handcraft sectors.

The Bhagaiya craft cluster in Jharkhand is one such example of where practices from regions of Kutch can be evaluated to be synthesized with the gaps prevailing in the region and make it move towards a much demanded handcrafted product not only restricted to India but Globally.

\section{Acknowledgments}

None.

\section{Funding}

None.

\section{Conflicts of interest}

The authors have no conflicts of interest regarding the publication of this paper.

\section{References}

1. Annual Report (2017-18). Ministry of textiles. Government of India; 2018 .

2. Agnihotri MP. Dead end at the silk road: the possible revival of the Banaras handloom industry. Prabandhan: Indian Journal of Management. 2015;8(8):30-38.

3. Bhalla K, Kumar T, Rangaswamy J. An integrated rural development model based on comprehensive life-cycle assessment (LCA) of KhadiHandloom industry in rural India. Procedia CIRP. 2018;69:493-498.

4. Banerjee AN, Pandit P, Maulik SR. Eco-friendly approaches to rejuvenate the Khadi udyog in Assam. 2019;18(2):346-350.

5. Ramchandra KP. Towards improving productivity of solapur based textsitles SMEs. 2015.

6. Pandit P, Gayatri TN, Maiti S. Green and sustainable textile materials using natural resources. Green and Sustainable Advanced Materials: Processing and Characterization. 2018;1:213-261.

7. Teli MD, Pandit P. Multifunctionalised silk using Delonix regia stem shell waste. Fibers and Polymers. 2017;18(9):1679-1690.

8. Teli MD, Pandit P. Application of Sterculia foetida fruit shell waste biomolecules on silk for aesthetic and wellness properties. Fibers and Polymers. 2018;19(1):41-54.

9. Maulik SR, Agarwal K. Painting on handloom cotton fabric with colourants extracted from natural sources. 2014;13(3):589-595.

10. Pandey R, Pandit P, Pandey S, et al. Solutions for sustainable fashion and textile industry. Recycling from Waste in Fashion and Textiles: A Sustainable and Circular Economic Approach. 2020;15:33.

11. Pandit P, Shrivastava S, Maulik SR, et al. Challenges and opportunities of waste in handloom textiles. Recycling from Waste in Fashion and Textiles: A Sustainable and Circular Economic Approach. 2020;15:123.

12. Maulik SR, Bhowmik L, Agarwal K. Batik on handloom cotton fabric with natural dye. 2014;13(4):788-794.

13. https://cgi.standrews.ac.uk/media/sasi/documents/Craft $\% 20$ and $\% 20$ Sustainable\%20Development.pdf

14. https://www.standrews.ac.uk/media/sasi/documents/Craft $\% 20$ and $\% 20$ Sustainable\%20Development.pdf

15. https://kutchcraftstudio.wordpress.com/craft-treasure/kharad-weaving/ 